\title{
Living Environment in Forcibly Isolated People: Lo-sheng Sanatorium in Taiwan
}

\author{
Masato Soda* \\ Ph.D. Candidate, Graduate Institute of Building \& Planning, \\ National Taiwan University, No.1 Sec.4 Roosevelt Rd. Taipei City 106, Taiwan
}

\begin{abstract}
The establishment of Lo-sheng sanatorium reflected force isolation policy of Hansen's disease (leprosy) in the colonial period. Although segregation policy substantively ended after 1970's, the residents faced difficulties in being reintegrated into society even after their disease cured, compelled to live there for their lifetimes. Under substantive segregation, they constructed the living environment themselves. This research clarifies the process of segregated site transformed into a self-sustaining community. The author not only has engaged in field surveys but supporting residents' movement, through unitizing accumulated participant observation works outcomes, can point out an example of sustainable self-build environments.
\end{abstract}

(c) 2016. The Authors. Published for AMER ABRA by e-International Publishing House, Ltd., UK. This is an open access article under the CC BY-NC-ND license (http://creativecommons.org/licenses/by-nc-nd/4.0/).

Peer-review under responsibility of AMER (Association of Malaysian Environment-Behaviour Researchers), ABRA (Association of Behavioural Researchers on Asians) and CE-Bs (Centre for Environment-Behaviour Studies), Faculty of Architecture, Planning \& Surveying, Universiti Teknologi MARA, Malaysia.

Keywords: Hansen's disease (leprosy) segregation; self-build environment; sustainable community

\section{Introduction}

Lo-sheng is a Hansen's disease (leprosy) sanatorium established in 1930 under Japanese colonial rule, reflected force isolation policy of Hansen's disease (also called as leprosy). After WWII, the sanatorium was also succeeded by the new government. Whether under the Empire of Japan or after KMT government relocation to Taiwan, the authorities had promoted the strict isolation policy of this disease, hence increased discriminations and stigmas against in the sanatorium. Although strict segregation policy substantively ended after 1970's, most residents of Losheng faced tremendous difficulties in being reintegrated into society even after their disease cured, compelled to live in a sanatorium for their lifetimes. Today we can find that self-built living environment in Lo-sheng is entirely

\footnotetext{
* Corresponding author. Tel.: +886-922-468-246

E-mail address: changren.masato@gmail.com
}

2398-4287 @ 2016. The Authors. Published for AMER ABRA by e-International Publishing House, Ltd., UK. This is an open access article under the CC BY-NC-ND license (http://creativecommons.org/licenses/by-nc-nd/4.0/).

Peer-review under responsibility of AMER (Association of Malaysian Environment-Behaviour Researchers), ABRA (Association of Behavioural Researchers on Asians) and cE-Bs (Centre for Environment-Behaviour Studies), Faculty of Architecture, Planning \& Surveying, Universiti Teknologi MARA, Malaysia.

DOI: http://dx.doi.org/10.21834/e-bpj.v1i3.348 
different from general hospitals. Under substantive segregation, they constructed facilities for everyday life, production, commerce, religion and recreation by themselves.

The entire premises of the sanatorium can be separate to the medical services zone, administration zone, staff quarters zone and residential zone of patients. The three former categories of areas were constructed by the official, in contrast, the last group, patient housing, has distinct features that include self-build facilities and the environment renovated by patients. Also, there also exist pre-fab temporary houses build in last dozen years.

The aim of this research is clarifying the process of segregated site gradually transformed into a self-sustaining community. In this article, the author makes an analysis of space using patterns in the residential area of patients. By reviewing the form of the spaces, the author explains the interaction between the residents and the living environment in historic transition, also explains the extraneous factors which brought about changes in attitudes of residents.

\section{Literature Review and Research Method}

An important part of studies on the issue of Le-sheng sanatorium is in Taiwan domestic except some Japanese scholars mentioned about the segregation policy in the colonial era. We can know operation process of segregation policy through the works of Taiwanese historians, Fan Yen-chiou (2008), (2009). Since Lo-sheng preservation movement has appreciably attracted attention among the younger generation in Taiwan, a considerable number of master's theses discuss this issue.

The author has been engaging in the effort for preserve this site over ten years, have accumulated substantial experiences of participant observation which include environmental survey and repetitive interviews with residents in a long term, and can adduce the characteristic features through these research, as well as some predecessors. For instances, Chang (2007) is a typical study outcome of participant observation from the viewpoint as an advocator of the reservation movements. Lin (2010) adopted the landscape and architecture study methodology, explored the value of 'home' of elder residents under preservation movement. Shen (2011) certified the sanatorium residents' self-resistance under the forced segregation policy through discourse analyzes, and moreover mentioned about the self-managed space as a representation of the resistance against isolation.

We can refer to overseas research outcomes for comparison. Some historians criticize the relevance between segregation policy and colonial modernization. Fujino (2001) explored the whole gamut of inhumane segregation policy by Japan Empire including in Korea, Taiwan, Mainland China and Southeast Asia. Gould (2005) and Edmond (2006) elucidated the development of segregation policy under modern colonialism. Loh (2009) revealed the history of Leprosy sanatoria in Singapore and Malaysia. Furthermore, we also can refer ethnographies of the patients in other countries. For example, Gaudet (2004) and Law (2012) recorded the experience of patients particularly and discussed the inheritance of memory.

We can benefit from a series of architectural research by Sakaino's team which based on long-term field studies (2001), (2007), (2013). They pointed out cases of autonomous house renovation in Hansen's disease segregation sanatoria in Japan. The author adopts a qualitative approach in this study for the following reasons: 1. Historical documents have limitations of single viewpoint by authorities. 2. The construction of Metro depot had destroyed the certain parts of the built environment. 3. Consciousness transformation is a gradual process through individual experience of every resident. Hence, the author thinks that methodologies of humanities are more applicable to this study.

\section{Basic Facilities of Lo-sheng: Planning and Operation in Earlier Days}

We can roughly classify the residential area of the buildings of this sanatorium into four groups. The first one includes the original houses which were begun to use with the opening of the hospital. Then, in the middle 1930s, many of the houses was built to cope with the sharp increase in the number of dwellers. These were constructed in the colonial period either. However, the style of architectures is different from the former ones. When it comes to after the Second World War, since sanatorium accommodated the veterans from mainland China, the authorities 
built some additional facilities; many of them are two-story houses. The last were houses designed for the sake of supporting the patients families to reintegrate into normal society in the 1970s. The overall layout of the sanatorium had spread radially from the medical facilities area as the core; the outer buildings were the newer ones. In these decades, because of the mass rapid transit system (Taipei Metro) depot construction work of the last few years, the relatively new buildings, which was in the outer part had been demolished earlier.

According to the floor plans of the first stage houses, officials crammed dozen of steel beds on both sides of the room. At the beginning of the operation, officials tend to accommodate 100-odd patients in these facilities entirely. After executing all new Leprosy Prevention Law in 1934, the colonial government implemented further punitive epidemic prevention actions, undertook screening of residents all over the island and also carried out a big campaign to segregate patients from the community into the hospital (Fujino, 2001, pp.357-363). Consequently, the number of the patients had increased sharply in a short period, caused a severe shortage of living space. On the second stage, the architectural design of houses became simpler than the first phase, on the other hand, possesses the characteristics in an architectural style which merged traditional Taiwanese floor plans and modern Japanese details. In these houses, the floor plans become several smaller rooms each building, nonetheless nearly ten persons had lived per bedroom. Except a steel bed, there only was a basin, tableware, and a small locker to put the personal belongings. Each patient had no private belongings but these facilities. The sanatorium has provided meals and use of the public bath, and the laundering of linens, clothes or gauzes, however, forced the patient to work. Furthermore, put a barbed-wire fence surrounding whole the site. Such kind of operating structure and living conditions have also generally continued after the end of colonial rule.

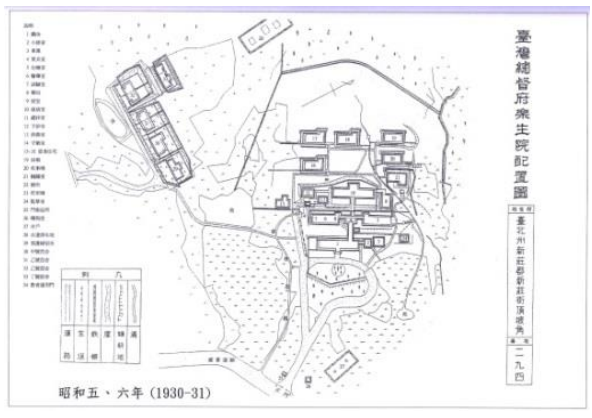

Fig. 1. (a) The overall layout in 1930;

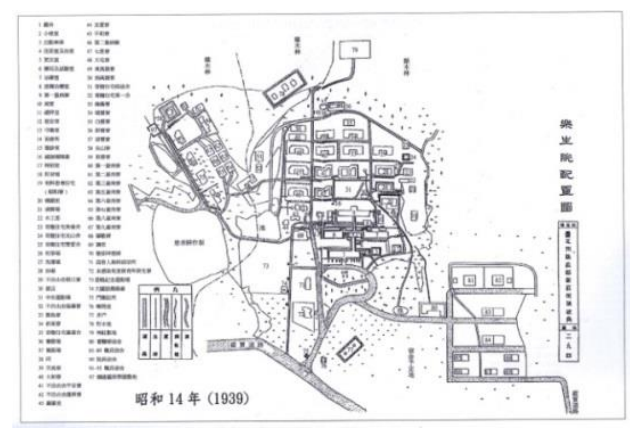

Fig. 1 (b) The overall layout in 1939.

After World War II, Kuomintang (China Nationalist Party, KMT) government succeeded the segregation policy designed by the Japanese government in principle, most of the patients who had admitted during the colonial period could not leave the hospital. Shortage of medical resources and daily commodities were getting more serious under the inchoate situation of postwar. In 1949, KMT central government relocated, taking with millions of troops, to Taiwan. The sanatorium began to accept a large number of Hansen's disease patients since then (Fan, 2009, pp. 122-123).

In 1954, the government assigned an army surgeon background doctor as new hospital director to resolve the unrest situation. He had carried out the management of military style, continued until his death in 1966. The prohibition of more absence without leave was the offender in prison. He also had done night off, and self-catering prohibition done strictly, turned all of the power of the dwelling zone past the off time of 22:00, the use of the electric fans even prohibited, when discovered using the stove to self-catering, confiscate it immediately. Under these steamroller administration, the social order in the sanatorium went to recover. At the same time, many of the dwellers felt the dissatisfaction to the management lacking humanity.

In this period, the officials replaced the beds with wooden ones, slightly increased the capacity for storing the personal belongings, did not provide the private space. They have to be in this asylum throughout the rest of their day whether their disease cured or not. That was because that not only some of cured patients' outward sequelae were so apparent but also social discriminations to the people who had resided Hansen's disease sanatorium. 


\section{Transition of Space and Self-build Environment}

In the residential area of the sanatorium, there not only are the housings for the patients but also exist other facilities necessary for every life. At the middle of the main street of dwelling zone, there is a small brick-made building which used to be a grocery store and a barber shop. The sanatorium officials have strictly controlled the patients outing thus they established consumers' cooperative society by themselves in the 1950s, also self-built the store building. Although the shop does not open in these years, it still is one of the most important landmarks in the sanatorium. There also was a small market opened before 2005, nevertheless was demolished in 2008.

We should not ignore the importance of religious sites. Missionary of the Presbyterian had been carried out charity activities through before and after WWII, but to build a formal church in 1952. Also, a considerable number of the patients had become Christians the reason that it is possible to receive the distribution of relief supplies from the United States. The church locates on the southern side of the whole sanatorium, had some adjunct facilities including a school and a vocational training workshop. Catholic also dispatched a priest and had established a church in 1965. Nevertheless, their missionary work was far from successful. The Buddhists, the number was much greater than Christians, did not have a dedicated worship facility before 1954. They are stimulated by church construction by Protestant, without receiving direct support from outside organizations, the congregation has built a temple on their own. Still now, an organization of the residents has operated this temple voluntarily. The location of the temple used to be a small plaza for the sake of obeisance to Imperial Palace in the colonial period. Originally, residents have been proactively managed the circumference environments of the religious area. In earlier days, Presbyterian Church had been running a school for the younger residents, established a workshop for residents who could not work outside. Today, these adjunct facilities are no longer in operation, and besides neighborhood ordinary people became a majority of church members. Buddhist residents used to celebrate Buddha's Birthday every year at this plaza, now just hold funeral ceremonies.

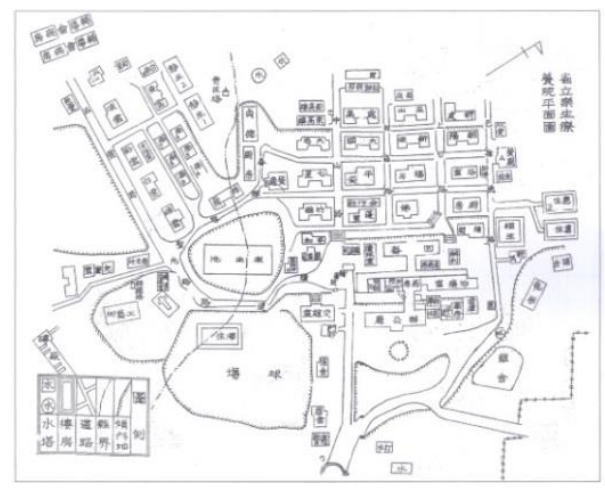

Fig. 2. (a) The overall layout in 1966

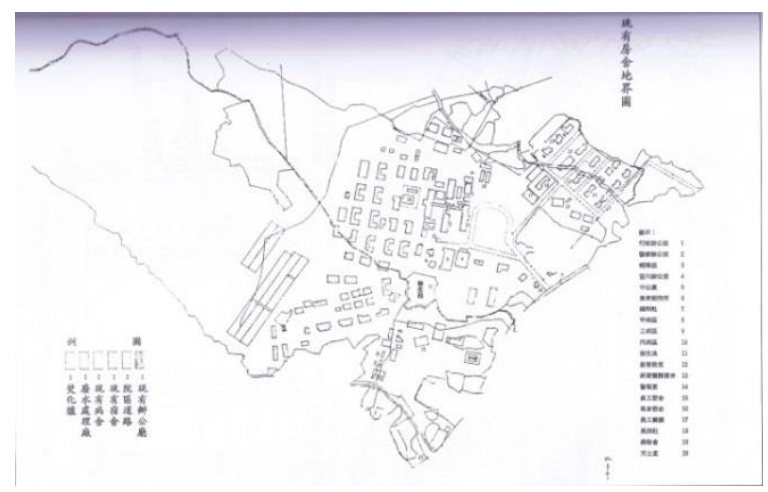

Fig. 2 (b) The overall layout in 1992.

After the 1960s, owing to the enough supply of curative medicine, an increasing number of patients got cured. The authorities had gradually loosened regulations. However, a considerable part of patients could not reintegrate into normal society because of prejudice and discrimination, on the other hand, did not provide adequate support to their everyday life. They have been constrained to depend only on their effort. Hence, each patient end up became a resident of Lo-sheng onwards, whether he/she wished or not. We can find common situations on residents of leprosy sanatorium in the 20 th century all over the world.

Today, we can find a clear difference in the use of space in the residential area and the therapeutic area. The former abounds in humaneness in contrast with the latter well-ordered. The author focuses on typical examples of the self-build environment in Lo-sheng to present some features of the space creation in this community. 
Due to the lack of space in each bedroom, the residents have been using eaves of houses extension of their personal space, generally, put storage racks or shoeboxes in front of the entrance. Some of them use there as kitchens or laundries, despite they even have communal facilities (fig. 3). It shows that aged and physically challenged residents have been reformed their living environment to accommodate demands in everyday life.

On the other hand, they utilize courtyard as their living room, put handmade tables and stools made of concrete under big banyan trees planted in front of each house (fig. 4). Most of these garden furniture are residents handmade. Some of them are under a simple canopy with corrugated metal roofs. There we can find elder residents enjoying teatime with their neighborhoods (fig. 5). Some residents plant flowers and vegetables in the small garden beside houses (fig. 6). They have common experiences of supplementing their meals with these vegetables in early days, thus, still like gardening and planting. The residents renovated the communal space as semi-private use style, under the wrong condition of living, and moreover still carry on. Today, when an outsider steps into this site, will feel it looks like a small village rather than a sanatorium. The people isolated from the normal society constructed sustainable living environment themselves.

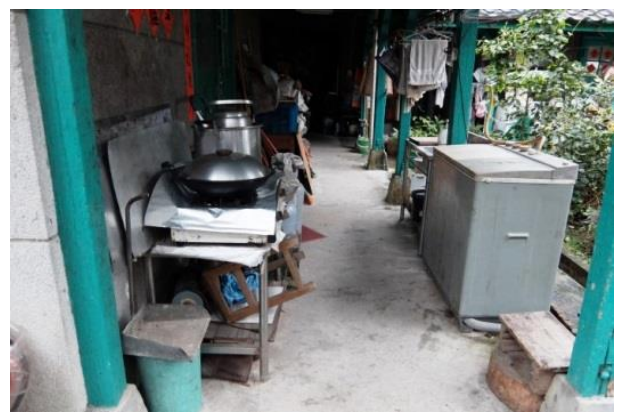

Fig. 3. A kitchen and a laundries machine in front of the entrance

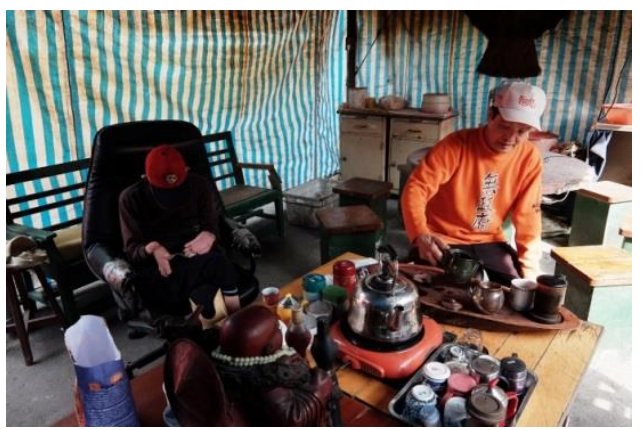

Fig. 5. Elder residents' teatime

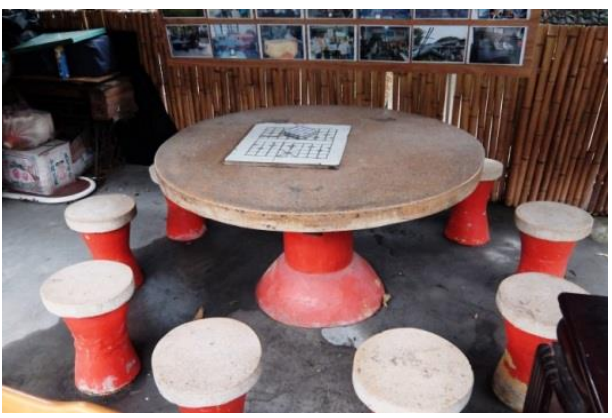

Fig. 4. A handmade table and stools

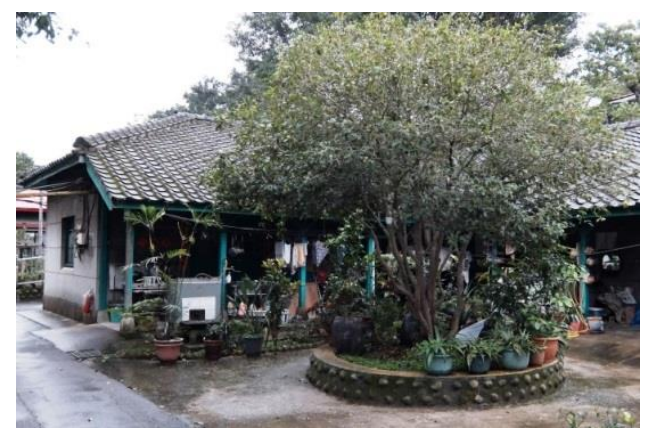

Fig. 6. A small garden beside an old house

\section{Changes in Recent Years: Aging of Residents and Facing the Crisis}

The drastic changes in the living environment brought about significant changes in consciousness of residents in the last few years. The sanatorium had faced a crisis with force demolition because of Metro depot construction at the outset of the 21st century. Although the residents voiced disagreement with unilateral decisions at planning phase in the 1990s, however, the government dismissed their claim. From 2003, in the first stage of the demolition, the buildings are located in the outermost portion had been demolished. There were many one-story tenement houses where residents lived with their children. They were forced to move to other houses in the sanatorium or go out. The department of Metro construction continuously moved on the next demolition stage at the staff quarters 
area and the abode of residents located in a southern west part of the site. After the momentum gathered for demolition, more and more residents come constrained to leave their house. Some of the them moved to pre-fab temporary housing.

The residents unavoidably evacuated from the place they lived for several decades. They realized that threat that they would lose their home and extensively stood up for the preservation of the site and living rights. This movement is continuing until today. At the begging of the struggles, they made efforts to let civil society know the historical particularity of this site, however, through the interaction with activists from outside, the residents rediscovered the value of this unique place, they empower themselves in parallel. When they have been aware of their residency rights and identities with the place, they no longer were the victims of isolation, became creators of the environment. They described this sanatorium as their 'second hometown', and obtained broad support from civil society in Taiwan.

At the middle of 2005 , the authorities opened the new hospital building beside the old sanatorium site, relocated the medical facilities and administration office there. Thus, a considerable number of residents, especially the aged and physically challenged residents, were compelled to move, whereas certain residents determined to stay in the old sanatorium area, organized self-help group under the firm support of younger generation social activist groups, aimed to achieve the site reservation and the sustainable living environment. The author also has participated in the social activities of supporting residents' movement, through unitizing accumulated participant observation works outcomes, can point out particular processes of interaction between humans and living environments.

\section{Conclusion}

This site is a practical example of self-built and self-sustainable environments. The residents also recognize this place as the bastion of their identities. Hayden (1997, p.46) states that "place memory encapsulates the human ability to connect with both built and natural environments that are entwined in the cultural landscape". The efforts for preserving Lo-sheng as cultural heritage are still continuing in Taiwan. The author believes that this research should contribute discourse for realizing unique pattern and a different value of the living environment and the cultural landscape.

From autumn in 2005, a part of the volunteer members started to engage in cultural activities; such as live concerts, theatrical performances, exhibitions, et cetera. At the first time the volunteers set up the platform stage for a music concert and other live performances, they encountered inhibition by the authorities, nevertheless were successful at the attendance of audience. In 2007, at the critical moment of the preservation movement, the activist group organized not only political campaigns but also live performances every weekend, attracted more people to this issue. During the struggle period, the atmosphere in the sanatorium was getting opener than before. We can believe someone will hand down this environment and its value to further generations even after the residents passed away.

\section{References}

Chang, Hsing-wen. (2007). Praxis of the social action against demolishing Lo-sheng sanatorium in Taiwan. (Master's thesis, National Yang Ming University, Taipei, Taiwan.)

Edmond, R. (2009). Leprosy and empire: a medical and cultural history. Cambridge University Press.

Fan, Yen-choiu (2008). Leprosarium and social identity of leprosy patients: the social history of leprosy in colonial Taiwan. Taiwan Historical Research. 15(4), 87-120.

Fan, Yen-choiu (2009). US aid medicine, Hansen's disease control policy, and patients' rights in Taiwan (1945-1960s). Taiwan Historical Research. 16(4), 115-160.

Fan, Yen-choiu (2014). Lo-shen leprosarium and leprosy medical research in modern Taiwan: relationship between medical research and leprosy control policy. Taiwan Historical Research. 21(1), 151-218.

Fujino, Yutaka. (2001). Hansen's disease patients who are persecuted in the name of "ethnic cleansing" - the modern history of "life". Kyoto: Kamogawa publication. 
Gaudet, M. G. (2004). Carville: Remembering leprosy in America. Jackson: University Press of Mississippi.

Gould, T. (2005). A disease apart: leprosy in the modern world. New York: St. Martin's Press.

Gussow, Z. (1989). Leprosy, Racism, and Public Health: Social Policy in Chronic Disease Control. Westview Press.

Hayden, D. (1997). The power of place: urban landscapes as public history. MIT Press.

Hirata, Katsumasa. (2008). A study on the problems of Hansen's disease in Taiwan during 1920s. Nagasaki Daigaku Kyoikugakubu Kiyo Kyoiku Kagaku, 72, 13-20

IDEA Taiwan (Ed.). (2012). Lingering dreams of younger days: 80th of anniversary of Lo-sheng. Taipei: Author.

Law, A. S. (2012). Kalaupapa: A collective memory. Honolulu: University of Hawaii Press.

Lin, Yu-ju. (2010). Dwell in Lo-sheng leprosarium: A transition from isolated medical space to the elderly home. (Master's thesis, Chung Yuan Christian University, Taoyuan, Taiwan.)

Loh, K. S. (2009). Making and unmaking the asylum: leprosy and modernity in Singapore and Malaysia. Petaling Jaya: Strategic Information and Research Development Centre.

Lo-sheng Sanatorium Oral History Working Group (Ed.). (2011). Lo-sheng: people from No.145 Dingpojiao. Taipei: Author.

Moran, M. T. (2007). Colonizing leprosy: imperialism and the politics of public health in the United States. Chapel Hill: University of North Carolina Press.

Sakaino, Kentaro., Miura, Ken., Kanki, Kiyoko., Takada, Mitsuo. (2007). House plans of an independent ward in a sanatorium for Hansen's disease and the extension and remodeling by the residents Journal of Architecture, Planning and Environmental Engineering,

Sakaino, Kentaro., Tomokiyo, Takakazu., Takada, Mitsuo. (2013). Changes in the facility planning for Hansen's disease sanatoriums under the leprosy prevention law. Journal of Architecture, Planning, 78(683), 45-53.

Sakaino, Kentaro., Yamazaki, Hiroki., Nakashima, Motoko., Miura, Ken., Toyama, Takashi. (2001). A study of historical change of the living environment of domitories in sanitarium for Hansen's disease. Journal of Architecture, Planning and Environmental Engineering, 66(546), 113-119.

Shen, Ya-wen. (2011). Power and Resistance: A discourse analysis of Lo Sheng Sanatorium in Forced Segregation Era (1945-1962). (Master's thesis, Soochow University, Taipei, Taiwan.) 